\title{
Numerical Investigations on the Ballistic Performance of Honeycomb Sandwich Structures Reinforced by Functionally Graded Plates
}

\author{
Recep Gunes ${ }^{1}$, Kemal Arslan ${ }^{2}$, M. Kemal Apalak ${ }^{3}$, J.N. Reddy ${ }^{4}$ \\ ${ }^{1}$ Department of Mechanical Engineering, Erciyes University, Kayseri 38039, recepg@erciyes.edu.tr \\ ${ }^{2}$ Department of Mechanical Engineering, Erciyes University, Kayseri 38039, karslan@erciyes.edu.tr \\ ${ }^{3}$ Department of Mechanical Engineering, Erciyes University, Kayseri 38039, apalakmk@erciyes.edu.tr \\ ${ }^{4}$ Department of Mechanical Engineering, Texas A\&M University, College Station, TX 77843-3123, USA, \\ jnreddy@tamu.edu
}

\begin{abstract}
This study investigates damage mechanism and deformation of honeycomb sandwich structures reinforced by functionally graded plates under ballistic impact effect by means of explicit dynamic analysis using ANSYS LS-DYNA. The honeycomb sandwich structures consisted of two identical functionally graded (FG) facesheets having different material compositions through the plate thickness and an aluminum honeycomb core. The functionally graded facesheets were composed of ceramic (SiC) and metal (A16061) phases. The through-thickness mechanical properties of facesheets were determined based on a power-law distribution of the volume fraction of the constituents. The locally effective material properties were evaluated using homogenization method which based on the Mori-Tanaka scheme. In the analyses, theoretical models which based on micro structural model of functionally graded materials were used. The effect of material composition of functionally graded facesheets on the ballistic performance of honeycomb sandwich structures was investigated and the penetration and perforation threshold energy values which are the most considerable parameters on ballistic performance and ballistic limit of the sandwich structures were determined.
\end{abstract}

Keywords: Functionally graded materials, honeycomb, sandwich structure, ballistic performance, finite element method.

\section{Introduction}

Sandwich structures are the oldest known form of composite material. It is formed by combining at least two different sheet materials in layer. Presence of sandwich structure in layers allows being formed different composite materials or different materials for each layer. By means of this, sandwich structures can be designed as ballistic armour structures. The FG reinforced plate disrupt the edge geometry of the bullet with reducing the ballistic effect by means of the ceramic surface of FGM, while the aluminum honeycomb core material provides the absorption of impact energy which affects the sandwich structure. Honeycomb composite structures are used for high mechanical strength structures which absorb the energy resulting from impact loads. By using the external FGM reinforcement plates and aluminum honeycomb core, the composite structure will have designed as both high mechanical strength and quite lightweight armour material.

In literature, many studies have been performed about mechanical responses of honeycomb sandwich structures under ballistic and high velocity impact loads [1-8], however, there is no study which is about a sandwich structure reinforced by FGM. Because of the honeycomb sandwich structures reinforced by functionally graded plates can be used for impacted environment under severe conditions as ballistic armour, it is very important to know the ballistic responses of this type structures. The purpose of this study is to analyze the ballistic performance of the sandwich structures with aluminum honeycomb core which is reinforced by functionally graded plates.

\section{Theoretical Model}

Ballistic impact of a steel projectile on honeycomb sandwich structure reinforced by functionally graded plates was examined by numerical simulations using ANSYS LS-DYNA [9] finite element code which is based on an explicit time stepping algorithm. The aluminum (3003 alloy) honeycomb core was assumed an elasto-plastic material and the material behavior is based upon the piecewise linear plasticity material model. The FG facesheets were modeled in three different through-thickness material composition variations $(\mathrm{n}=0.1,1.0$, and 10.0) which determine the through-thickness variation of ceramic constituent is linearly or nonlinearly. The locally effective material properties of the FG facesheets were determined 
using the Mori-Tanaka homogenization scheme. The bottom layer of the plates is elasto-plastic pure metal (Al6061) and the top layer is linear-elastic ceramic ( $\mathrm{SiC}$ ) with volume fraction of $70 \%$. In order to describe the elasto-plastic behavior of a metal/ceramic FGM the TTO model was used. Thus, the failure strains in all layers were determined using TTO model in order to predict the damages each layer through the thickness of FG plates under ballistic impact. Figure 1 shows the stressstrain $(\sigma-\varepsilon)$ curves obtained from TTO Model for an Al/SiC FGM system with metal-rich $(\mathrm{n}=0.1)$, linear $(\mathrm{n}=1.0)$ and ceramic-rich $(\mathrm{n}=10.0)$ composition variations [10].

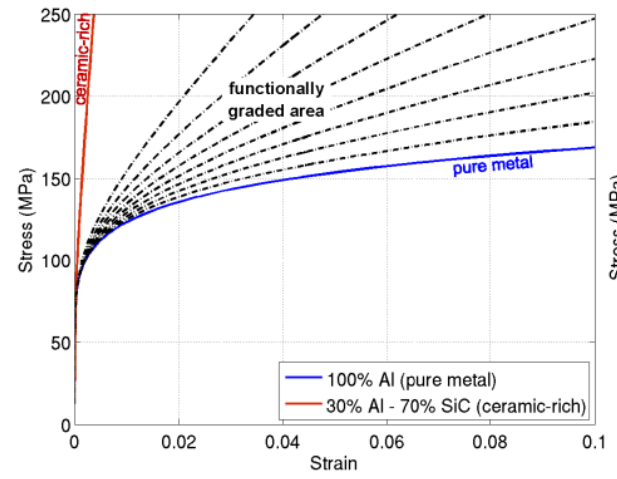

a) $\mathrm{n}=0.1$

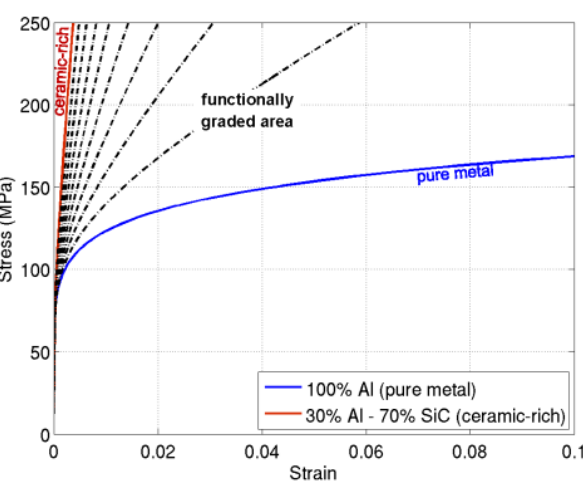

b) $\mathrm{n}=1.0$

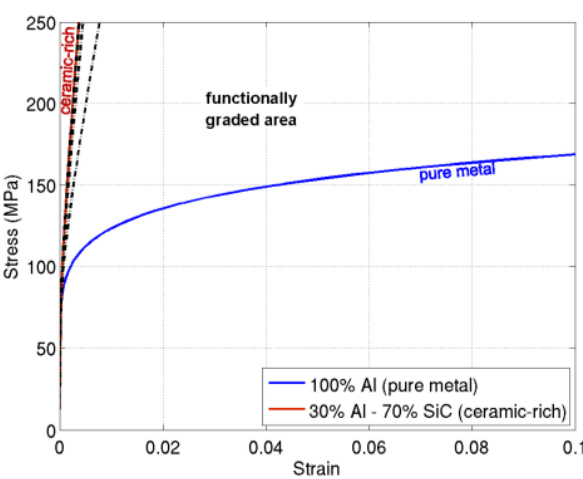

c) $\mathrm{n}=10.0$

Figure 1: Stress-strain curves from the TTO model for a) metal-rich $(n=0.1)$, b) linear $(n=1.0)$ and c) ceramicrich $(\mathrm{n}=10.0) \mathrm{Al} / \mathrm{SiC}$ FG material [10].

For the $56 \mathrm{~mm} \times 56 \mathrm{~mm}$ sandwich structures, the aluminum honeycomb core had a cell size of $6.35 \mathrm{~mm}$, foil thickness of $0.07 \mathrm{~mm}$ and a core height of $18 \mathrm{~mm}$. Each FG facesheet measured $5 \mathrm{~mm}$ thick. Ballistic impact was carried out with 0.30 caliber Fragment Simulating Projectile (FSP) defined by STANAG-2920 and MIL-DTL-46593B (MR) [11] on honeycomb sandwich structure reinforced by FG plates. Plastic Kinematic material model was used for projectile [12]. The mechanical properties of Al honeycomb, constituents of FG plate and projectile are listed in Table 1. The top and bottom facesheets and projectile were meshed with SOLID164 elements, while the honeycomb sandwich core was meshed with SHELL163 elements. The FG facesheets were modeled using 10 layers through the thickness. Because of both the time of the threedimensional calculations with the finite element code and the size of the results files, each layer is modeled by one element in the plate thickness. The finite element model of the honeycomb sandwich structure reinforced by FG plates and the projectile used is shown in Figure 2. All edges of sandwich structure were constrained from their normal and vertical plane.
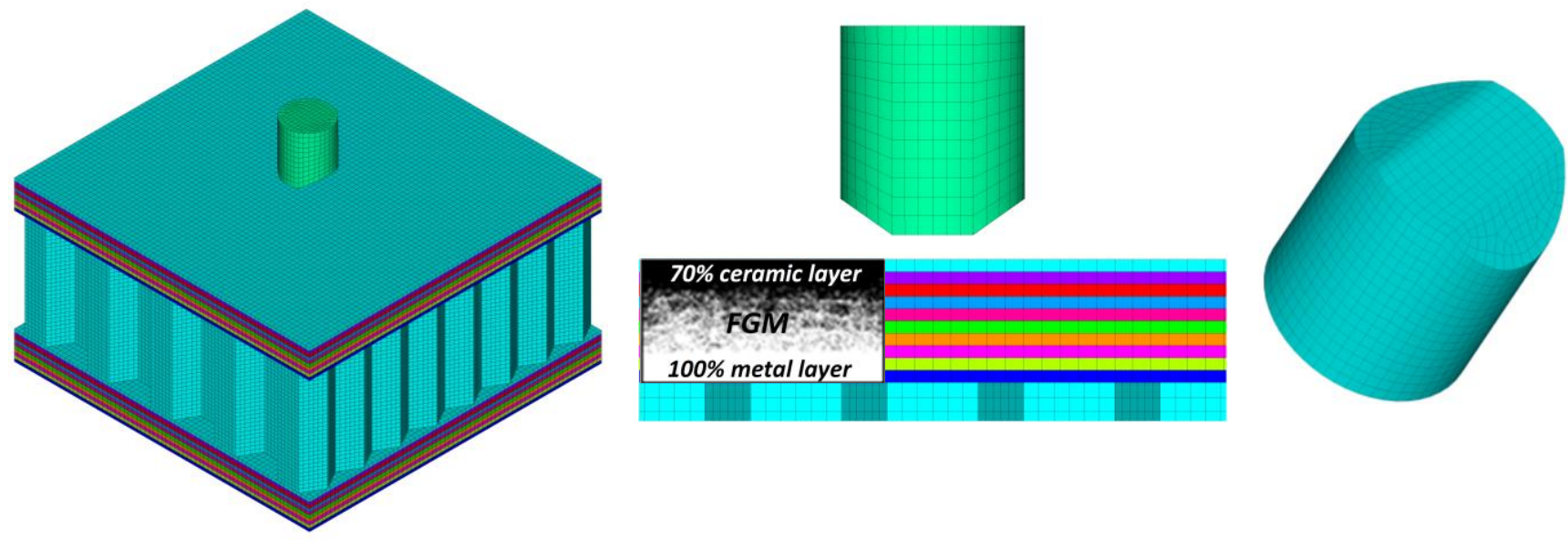

Figure 2: Finite element models of the honeycomb sandwich structure reinforced by FG plates and projectile.

Contact modeling is critical for predicting the ballistic response of armor structures. In this study, an ERODING_SINGLE_SURFACE contact was defined in order to take into account self-contacting interfaces during the projectile impact process. An ERODING_SURFACE_TO_SURFACE contact definition was defined between the projectile and the sandwich structure with the static and dynamic friction coefficients of 0.3 and 0.2 , respectively. Moreover, the contacts were assumed to be perfectly bonded between honeycomb core and FG plates. Thus TIED_NODES_TO_SURFACE contact algorithm was defined between honeycomb core and FG facesheets. 
Table 1. Material properties of constituents of FG plate, honeycomb and projectile.

\begin{tabular}{|c|c|c|c|c|c|c|}
\hline Materials & $\begin{array}{l}\text { Young's } \\
\text { Modulus (GPa) }\end{array}$ & $\begin{array}{l}\text { Poisson } \\
\text { Ratio }\end{array}$ & $\begin{array}{l}\text { Density } \\
\left(\mathrm{kg} / \mathrm{m}^{3}\right)\end{array}$ & $\begin{array}{l}\text { Yield } \\
\text { Stress (MPa) }\end{array}$ & $\begin{array}{l}\text { Tangent } \\
\text { Modulus (MPa) }\end{array}$ & $\begin{array}{l}\text { Failure } \\
\text { Strain }\end{array}$ \\
\hline Al-6061 & 67 & 0.33 & 2702 & 95 & - & 0.62 \\
\hline $\mathrm{SiC}$ & 302 & 0.17 & 3100 & - & - & 0.005 \\
\hline Al-3003 & 70 & 0.33 & 2730 & 183 & - & 0.52 \\
\hline AISI 4340 & 200 & 0.29 & 7850 & 970 & 470 & 0.77 \\
\hline
\end{tabular}

\section{Results}

The effect of the compositional gradient exponent " $\mathrm{n}$ " on the ballistic performance of honeycomb sandwich structures reinforced by FG plates was investigated for $\mathrm{n}=0.1,1.0$, and 10.0. The fragment simulating projectile (FSP), defined by STANAG-2920 and MIL-DTL-46593B (MR), was used to determine the $\mathrm{V}_{50}$ and the ballistic limit. Lambert-Jonas equation defined as

$$
V_{R}=A \cdot\left(V_{I}^{p}-V_{50}^{p}\right)^{1 / p}
$$

where $V_{R}$ is residual velocity, $V_{I}$ is impact velocity and $V_{50}$ is the ballistic limit velocity. $A$ and $p$ are empirical parameters depending on material. Variations of residual velocity of the projectile as a function of the impact velocity for the metal-rich $(n=0.1)$, linear $(n=1.0)$ and ceramic-rich $(n=10.0)$ material compositions of the FG facesheets were presented in Figure 3. According to Lambert-Jonas equation, when the residual velocity is zero, impact velocity becomes equal to the ballistic limit velocity. A series of ballistic analysis were performed to determine the residual velocity is zero for all compositional gradient exponents ( $\mathrm{n}=0.1,1.0$, and 10.0) of the FG facesheets. Consequently, the sandwich structure with $\mathrm{n}=10.0$ exhibits the highest ballistic limit, which is estimated to be $674 \mathrm{~m} / \mathrm{s}$. For the $\mathrm{n}=1.0$, sandwich structure have a ballistic limit of $628 \mathrm{~m} / \mathrm{s}$, and the honeycomb sandwich structure reinforced by metal-rich $(\mathrm{n}=0.1) \mathrm{FG}$ facesheets results in a ballistic limit value of $485 \mathrm{~m} / \mathrm{s}$. It is also observed from Figure 3 that the residual velocities increase with increasing impact velocities for material composition values of $0.1,1.0$ and 10.0. Figure 4 shows the kinetic energy variations corresponding to the ballistic limit velocities of the projectile for the metal-rich $(n=0.1)$, linear $(n=1.0)$ and ceramic-rich $(n=10.0)$ material compositions of the FG facesheets. Kinetic energy variations can be identified in three stages for all compositional gradient exponents $(\mathrm{n}=0.1,1.0$ and 10.0). First stage, projectile's kinetic energy shows a sudden drop due to perforation of the top FG facesheet. In stage II, perforation of the honeycomb core occurs and kinetic energy of the projectile remains almost the same level. In stage III, the trend of projectile's kinetic energy is similar to those of the stage I, and the last stage is completed by perforation of the bottom FG facesheet. At the end of the third stage, the projectile's kinetic energies are equal to zero for the metal-rich $(n=0.1)$, linear $(\mathrm{n}=1.0)$ and ceramic-rich $(\mathrm{n}=10.0)$ material compositions of the FG facesheets.

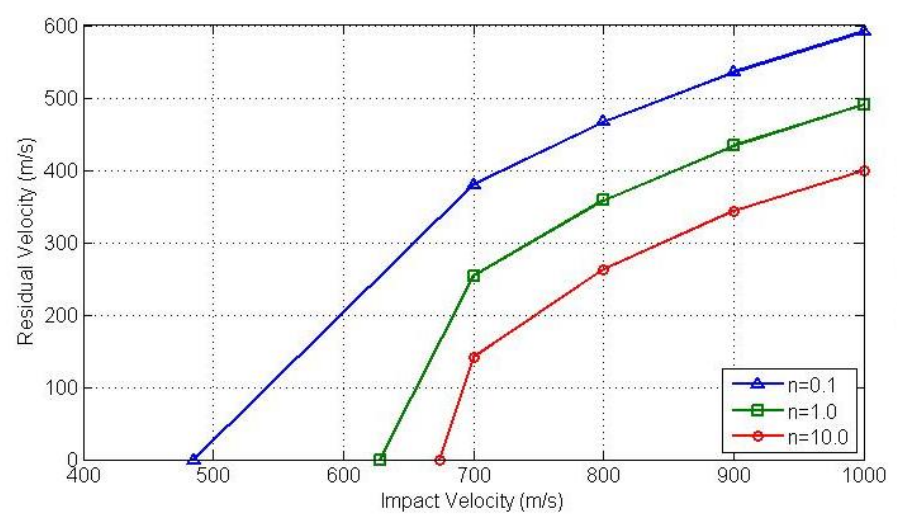

Figure 3: Residual velocity versus impact velocity of projectile for a) metal-rich $(n=0.1)$, b) linear $(n$ $=1.0)$ and $\mathrm{c})$ ceramic-rich $(\mathrm{n}=10.0) \mathrm{Al} / \mathrm{SiC} \mathrm{FG}$ facesheets.

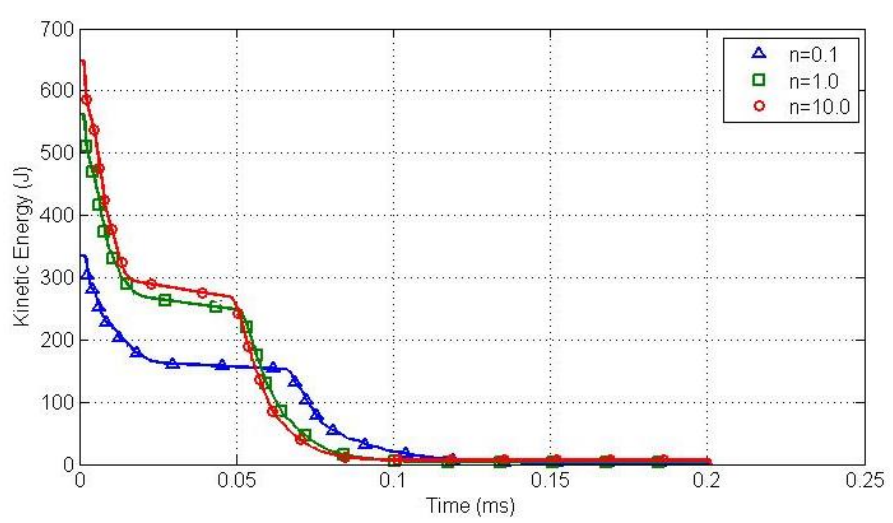

Figure 4: Kinetic energy variations of projectile for a) metal-rich $(n=0.1), b)$ linear $(n=1.0)$ and c) ceramic-rich $(\mathrm{n}=10.0) \mathrm{Al} / \mathrm{SiC}$ FG facesheets.

Figure 5 shows simulated damage sequence of honeycomb sandwich structure reinforced by metal-rich ( $\mathrm{n}=1.0) \mathrm{FG}$ facesheets during perforation by a 0.30 caliber Fragment Simulating Projectile (FSP) which has impact velocity of $628 \mathrm{~m} / \mathrm{s}$. The perforation process took approximately $0.172 \mathrm{~ms}$.

\section{Conclusios}

In this paper, ballistic limit velocities were investigated numerically honeycomb sandwich structures reinforced by FG facesheets featuring three types of material composition $(\mathrm{n}=0.1,1.0$ and 10.0) under ballistic impact. Numerical analyses 


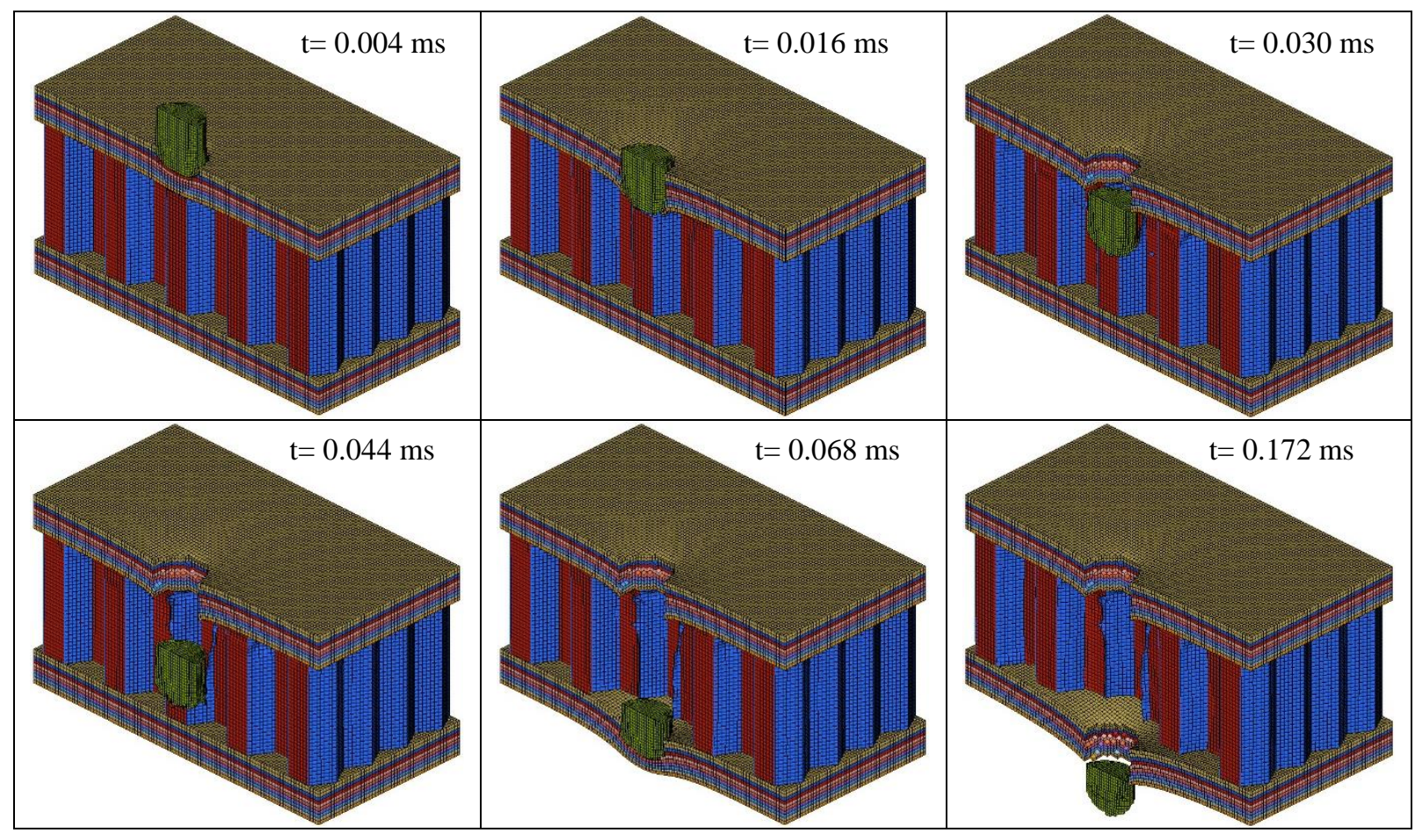

Figure 5: Simulated damage sequence of honeycomb sandwich structure reinforced by FG facesheets ( $\mathrm{n}=1.0)$ perforated by a 0.30 caliber Fragment Simulating Projectile (FSP).

were performed using ANSYS LS-DYNA explicit dynamics product. The projectile's initial velocity is equal to the ballistic limit when the total energy absorbed by sandwich structure is equal to the initial kinetic energy of the projectile. Thus, in order to determine the ballistic limit velocities of honeycomb sandwich structures reinforced by FG plates having metal-rich $(\mathrm{n}=0.1)$, linear $(\mathrm{n}=1.0)$ and ceramic-rich (10.0) material compositions, a series of ballistic analyses were performed by a 0.30 caliber Fragment Simulating Projectile (FSP). Numerical results show that the perforation resistant capability of honeycomb sandwich structures reinforced by FG facesheets increases with increasing compositional gradient exponent of FG plates. In addition, the honeycomb core between the FG facesheet has an important contribution on the ballistic performance of the structure by ensuring the integrity of the armor structure and by absorbing the energy of projectile.

\section{Acknowledgements}

The authors would like to acknowledge funding from the Scientific and Technological Research Council of Turkey (TUBITAK) under the research Grant No. 112M917.

\section{References}

1.J.M. Sibeaud, L. Thamié, C. Puillet, Hypervelocity impact on honeycomb target structures: Experiments and modeling. International Journal of Impact Engineering. 35 (2008) 1799-1807.

2. S. Ryan, F. Schaefer, R. Destefanis, M. Lambert, A ballistic limit equation for hypervelocity impacts on composite honeycomb sandwich panel satellite structures. Advences in Space Research. 41 (2008) 1152-1166.

3. T. Wang, M. Ma, W. Yu, S. Dong, Y. Gao, Mechanical Response of Square Honeycomb Sandwich Plate with Asymmetric Face Sheet Subjected to Blast Loading. Procedia Engineering. 23 (2011) 457-463.

4. B.L. Buitrago, C. Santiuste, S. Sánchez-Sáez, E. Barbero, C. Navarro, Modelling of composite sandwich structures with honeycomb core subjected to high-velocity impact. Composite Structures. 92 (2010) 2090-2096.

5. S. Feli and M.H.N. Pour, An analytical model for composite sandwich panels with honeycomb core subjected to high-velocity impact. Composites: Part B. 43 (2012) 2439-2447.

6. M.D. Theobald, G.S. Langdon, G.N. Nurick, S. Pillay, A. Heyns, R.P. Merrett, Large inelastic response of unbonded metallic foam and honeycomb core sandwich panels to blast loading. Composite Structures. 92 (2010) 2465-2475.

7. P. Kang, S.K. Youn, J.H. Lim, Modification of the critical projectile diameter of honeycomb sandwich panel considering the channeling effect in hypervelocity impact. Aerospace Science and Technology. 29 (2013) 413-425. 
8. W. Schonberg, F. Schäfer, R. Putzar, Hypervelocity impact response of honeycomb sandwich panels. Acta Astronautica. 66 (2010) $455-466$.

9. ANSYS LS-DYNA ${ }^{\circledR}$. The general purpose finite element software. Houston, Texas: Swanson Analysis Systems, Inc.

10. R. Gunes, M. Aydin, M.K. Apalak, J.N. Reddy, Experimental and numerical investigations of low velocity impact on functionally graded circular plates. Composite: Part B. 59 (2014) 21-32.

11. MIL-DTL-46593 B (MR). (11 August 2008).

12. Nechitalio and R.C. Batra, Penetration of steel plates by long ceramic rods. Metalurgical and Materials Applications of Shock-Wave and High-StrainRate Phenomena. 64 (1995) 543-550. 